\title{
An exploration of the current status of information literacy tuition in South African tertiary institutions and proposals for curriculum design
}

\author{
Karin de Jager and Mary Nassimbeni \\ Department of Information \& Library Studies, Centre for Information Literacy, \\ University of Cape Town, Rondebosch 770I, South Africa \\ kdejager@ched.uct.ac.za\&mnassimbeni@ched.uct.ac.za
}

\begin{abstract}
Received: 20th November 2002
Revised: IOth March 2003

An investigation was launched at the University of Cape Town (UCT) with the aim of determining measurable competencies in students' information literacy at tertiary level educational institutions. It is increasingly clear that students need both technological skills and information competencies in order to access and employ a wide range of electronic and other information resources. As courses are being developed to inculcate these competencies, it is imperative to generate and incorporate a rationally justified system of standards and benchmarks according to which the outcomes and impact of such interventions may be measured and evaluated in order to ensure continuous improvement. Members of staff at the Centre for Information Literacy at UCT are working towards the establishment of such standards and intend making them available to the information community throughout southern Africa in order that best practice may be shared by all. This paper specifically reports on two exploratory surveys in which firstly, responses were received from ten different information literacy providers from a number that had been identified at the 200I LIASA conference, and a follow-up survey at the 2002 LIASA conference. It concludes with a suggested approach to obtaining consensus on preliminary standards for information literacy among South African students and a process of evaluation.
\end{abstract}

\section{Information Literacy Standards}

During the 1990s, at least partly in response to rapid developments in the field of information technology, the information and library profession began to note the increasing importance of information literacy and recognised the need for standards and benchmarks with which to measure competencies. In 2000 the Association of College and Research Libraries (ACRL) published a set of five 'Information Literacy Competency Standards' for the United States. Similarly, the Standing Council of National and University Libraries (SCONUL) in the United Kingdom published a Seven Pillars Model of Information Literacy which details the seven major information skills required by all students (1999). The Council of Australian University Librarians published their own adapted 'Information Literacy Standards' in 2001. Essentially, there seems to be agreement that the information literate person is one who:

I. Recognises a need for information

2. Accesses needed information effectively and efficiently

3. Evaluates information and its sources critically

4. Incorporates selected information into her/his knowledge base

5. Uses information effectively to accomplish a specific purpose

6. Understands economic, legal and social issues; uses information ethically and legally

7. Recognises that lifelong learning and participative citizenship require information literacy (This is an Australian addition to standards that are otherwise very similar to the American version).

In 1996 the Cape Library Co-operative (CALICO) had been instrumental in launching a large information literacy needs assessment study, the results of which were published as a monograph by Yusuf Sayed (1998). It reported on a major overview of the state of information literacy on five tertiary education campuses in the Western Cape and revealed the significant discrepancies between students from historically disadvantaged and historically white universities. Sayed (1998: 6-7) made it clear that information literacy teachers in the South African context should recognise the fact that all students have not had equal prior access and exposure to educational resources of all kinds. The same opportunities to develop skills that might be taken for granted in school leavers in the USA, the UK or Australia, were not available to the majority of entrants into South African tertiary institutions. Students bring to higher education a set of previous experiences, beliefs and disciplinary traditions that may either hinder or enhance their learning and these should be taken into consideration in activities aimed at developing information literacy in students.

In addition, it was emphasised by early findings of the study that the skills required for information literacy might not necessarily be generic or easily transferable but 'highly dependent on context' and that as the tools and ways of handling information are in a constant state of change and development (Sayed and De Jager, 1997: 9), teaching information skills should be firmly embedded in subject knowledge. It might therefore follow that so-called 'generic' courses that are not 
firmly integrated into the curricula of specific courses might be less appropriate for inculcating information skills of lasting value in South African students.

In response to these information literacy initiatives, therefore, South African teachers and librarians began to understand that while the literature on information literacy from the English-speaking world might be relevant to local circumstances, South African students come to the world of information and to tertiary education with specific and often severe disadvantages that might not be as evident in other parts of the world. It should therefore follow that information literacy interventions and assessment should be specifically designed for the requirements of the South African student body.

\section{Benchmarking information literacy}

The practice of benchmarking, a strategic assessment tool common in the business environment essentially consists of comparing one's own practice with best practice in order to ensure continuous improvement. It involves the establishing of a standard of excellence against which similar practices or procedures may be measured. An essential requirement for a successful benchmarking enterprise is a deep understanding of the area to be benchmarked and for it to be broken down into its constituent and measurable elements. The purpose of benchmarking is to improve the current situation in order to attain excellence. An important product of such an initiative is 'the discovery of innovative approaches ... as enhancement of current practices is rarely sufficient to ensure future excellence' (Meade, 1998: 3).

The establishment of best practice is a time-consuming process and particularly problematic in an environment where some doubt exists as to what constitutes best practice, or where consensus does not exist over how it is to be achieved. The whole area of information literacy may be regarded as such an area. A great deal has been written about information literacy and every librarian knows that the desired outcome of all bibliographic instruction and user training, is the information literate user and lifelong learner. Yet very little has been done that shows objectively and measurably how this ideal may best be attained.

\section{Information literacy in South Africa}

In order therefore, to begin to establish possible benchmarks that could guide librarians and teachers towards the best practices for inculcating information literacy in the extremely diverse South African student body, it was deemed essential to consult with identified local practitioners to discover the nature and content of current practice, and how and whether students were being assessed and evaluated at present. The time for such an investigation was particularly appropriate as all higher education institutions are currently engaged in curriculum reform to bring their academic programmes in line with the National Qualifications Framework of the South African Qualifications Authority (SAQA).

SAQA was established in terms of the National Qualifications Framework Act of 1995. The National Qualifications Framework is "the set of principles and guidelines by which records of learner achievement are registered to enable national recognition of acquired skills and knowledge, thereby ensuring an integrated system that encourages life-long learning." (SAQA, 2000).

SAQA has adopted a number of cross-field critical outcomes which are reflected in the National Qualifications Framework. These generic outcomes are deemed to be essential for the development of the capacity for lifelong learning and are expected to be incorporated into specific qualifications. These outcomes include the expectation that a student should exit from higher education with the following competencies or the ability to:

I. "Identify and solve problems in which responses display that responsible decisions using critical and creative thinking have been made;

2. Work effectively with others as a member of a team, group, organisation, community;

3. Organise and manage oneself and one's activities responsibly and effectively;

4. Collect, analyse, organise and critically evaluate information;

5. Communicate effectively using visual, mathematical and/or language skills in the modes of oral and/or written presentation;

6. Use science and technology effectively and critically, showing responsibility towards the environment and health of others;

7. Demonstrate an understanding of the world as a set of related systems by recognising that problem-solving contexts do not exist in isolation" (South African Qualifications Authority, 2000)

Keeping in mind therefore the skills and abilities expected from the information literate person and informed by the critical cross-field outcomes (the fourth bullet point in particular) required for lifelong learning by SAQA, a list of information literacy competencies was compiled, based on a benchmarking breakdown by Godwin (200I) and consistent with other established standards for information literacy, such as those published by the ACRL and Australia. A study of 
these standards had confirmed that the selected competencies could indeed be regarded as the basic yet most essential component parts of the construct of information literacy.

Writers on information literacy have consistently emphasised that the construct encompasses both lower and higher order skills as was originally analysed in Bloom's 'Taxonomy of Educational Objectives' which requires that students first master the cognitive skills of the lower levels of each knowledge domain before the higher order skills may be mastered (Haberle, 200 I: 49). This taxonomy was further developed for the analysis of library and information skills by making provision for the progression from lower order to higher orders skills in three graduated steps: from orientation to interaction to internalisation (Haberle 200I: 50). The basic abilities and graduated skills were enumerated as follows:

Orientation

I. To recognise a need for information

2. To define a topic as a preliminary step in the search for information

3. To select the main concepts in a topic

4. To identify keywords to search for information on a topic

5. To understand that a range of information sources is needed to research a topic

Interaction

6. To know that general reference sources may be used to gain a broad understanding of a topic

7. To know that different kinds of information will be found in different kinds of sources

8. To be able to choose the most appropriate resources; both print and electronic

9. To be able to distinguish between catalogues, indexes, online databases and web resources

10. To be able to locate and access information from different resources

II. To know how to formulate search strategies

12. To be able to construct search statements

13. To use Boolean logic

14. To know how search engines work

15. To quote and cite others' work correctly

16. To know about issues such as copyright and plagiarism

17. To know about issues such as currency, bias and authority

Internalisation

18. To be able to compare and evaluate information from different resources

19. To be able to organise, use and communicate information

20. To produce and present an organised piece of work

21. To synthesise and build new knowledge based upon existing information.

In the list above, I - 5 are the lower order orientation skills which enable students to situate themselves in the world of information; 6 - 17 are intermediate level skills which demand interaction with information resources and could vary significantly from discipline to discipline. The higher order skills, abilities and knowledge $(18-20)$ require internalisation of what has been learnt and will not be adequately internalised without a firm grasp of the preceding steps.

\section{Investigating current practice}

At the conference of the Library and Information Association of South Africa (LIASA) in September 200I, it had been agreed that user education and information literacy would be a focus area of the Research, Education and Training Interest Group (RETIG). A significant number of different tertiary education institutions were represented at this meeting and identified themselves as either interested in providing information literacy training or as already active practitioners. In order to proceed with this investigation towards the benchmarking of information literacy, an e-mail questionnaire was designed to assess the extent of institutional support for information literacy at twenty-six identified institutions of tertiary education in South Africa, as well as to investigate the nature and extent of information literacy activities that could be identified.

Twelve tertiary institutions in South Africa responded to this electronic survey: seven universities and five technikons. While this overview therefore could not claim to exemplify all information literacy initiatives in SA, it was nevertheless regarded as indicative of the process and development of interventions by identified enthusiastic participants at South African tertiary education institutions. The results of this investigation were published by De Jager and Nassimbeni, (2002a) and reported at the next LIASA conference (2002b).

At this particular conference presentation, a further brief questionnaire was distributed among the attendees in an attempt to obtain a further indication of consensus on what the electronic questionnaire results had indicated were the 
most significant issues. A total of 50 questionnaires were distributed, of which 32 (64\%) were returned. Of these, 19 responses came from tertiary education institutions; the other 13 were mainly from schools and other institutions with educational functions (public libraries; the Library of Parliament; the British Council). Seventeen respondents indicated that they were librarians involved in information literacy training activities, nine were librarians interested in information literacy but not actually involved with teaching or training activities. Taken together, these two surveys may therefore be regarded as a reflection of the current situation with regard to information literacy activities at South African institutions of tertiary education.

The first question in the original questionnaire had inquired about the extent to which the respondents' parent institutions had shown any strategic awareness (as expressed in strategic plans or policy statements) of the importance of information literacy in their institutions as a result of repeated government emphasis on the prioritising of issues related to information literacy such as the inculcation of generic skills and recognition of prior learning (South Africa. Department of Trade and Industry, 2000).

Responses had indicated that there was little explicit evidence of institutional strategic plans or policy statements that specifically acknowledge a responsibility for inculcating information literacy in students. The second questionnaire therefore followed up on this point by asking respondents whether they thought information professionals should lobby for institutional support for information literacy at the highest levels in their institutions. This was supported by all the respondents.

The original questionnaire was intended to reveal where the locus of information literacy activities resided in South African tertiary institutions: in the libraries, in academic development divisions, in departments of communication or information studies, or in academic departments. Responses had provided evidence of a measure of co-operation between the various libraries and academic departments. At institutions that had departments of communication or information studies (or information science), the departments co-operated with the libraries in the delivery of courses or themselves offered dedicated courses. The second survey strongly corroborated support for such co-operation: 30 respondents agreed that information literacy activities should be the result of collaboration between academic and library staff, while only nine (28\%) regarded such teaching as the sole responsibility of librarians.

The issue of generic courses as opposed to courses integrated into the curriculum was considered in both surveys. The original questionnaire asked whether current courses were offered as stand-alone modules or integrated into subject curricula and investigated further issues such as assessment and credit and methods of course delivery.

Responses were mixed in both cases. The first survey received reports of both stand-alone and generic courses as well as attempts at integrating courses into subject curricula, although where a measure of integration took place, it was mainly in the form of subject librarians presenting sessions on subject-specific reference materials and information sources. The second survey confirmed that the most support was for integrating information literacy into subject curricula (26 responses, $81 \%$ ), although substantial support for generic, stand-alone courses was in evidence as well (2I responses, $66 \%$ ). Annotations to questionnaires confirmed that some respondents were of the opinion that generic courses were still valuable at the initial stages or basic levels, or where information literacy skills were not (yet?) taught as part of subject curricula.

Responses to both surveys provided evidence of a need for assessment in information literacy courses. In the initial investigation, seven institutions reported offering fully assessed courses, three reported some assessment and two none. Where credit-bearing courses had been introduced, they were fully assessed, by means of assignments, tests, portfolios or examinations; otherwise questionnaires or course evaluation forms were used by all but two of the respondents. In the second survey, 30 respondents (94\%) agreed that assessment is required after training courses.

Interestingly, the first survey had found that where courses were assessed, they were not necessarily credit-bearing; four institutions assessed courses that bore no credit. The follow-up survey found that 28 respondents (88\%) thought that courses should indeed be credit bearing.

Both surveys then provided a list of information literacy competencies, which was drawn up to represent both the 'lower order' and the 'higher order' information skills as discussed above. Respondents were requested to mark and where necessary, comment on all that were taught in their institutions.

In the first survey, seven institutions had reported that they taught all of them. The other five did not teach "how search engines work' or the 'higher order' information literacy skills of evaluation, communication, production, presentation and synthesis of information, although two institutions mentioned that these skills were taught by the academic departments and not by the library; while two suggested that they were not really taught at all.

In the second survey, 20 of the 32 respondents completed this section. Of the 20 , only two replied that they taught all of them. The competencies that were most often taught ( 17 or more responses out of 20 ) were:

- To identify a research topic or an information need; 
- To select main concepts and key terms;

- To choose a range of most appropriate and subject specific information sources;

- To construct search statements;

- To use Boolean logic where appropriate.

Competencies that were ticked by 14 or 15 respondents were:

- To define the topic, ensuring manageable focus;

- To explore general information sources to become familiar with the topic;

- To select information that is at the right level and fulfills the information need;

- To maintain a list of information sources used;

- To quote and cite others' work correctly;

- To understand copyright and to avoid plagiarism;

- To be able to compare and evaluate information from different resources.

Competencies that were ticked by 10 or II respondents were:

- To formulate strategies appropriate for searching the Worldwide Web;

- To understand the importance of currency and authority; recognising bias;

- To be able to organise, use and communicate information;

- To produce and present an organised piece of work .

The competency 'To synthesise and build new knowledge' was ticked by nine respondents, and six said they taught how to 'deal with an overload of information'.

From the responses to both surveys, it is possible to conclude that certain core competencies are well-embedded in information literacy curricula in South Africa. There seems to be consensus that the activities related to orientation, and interaction with information sources, are well established, although it also seems that there is some doubt about dealing with skills relating to the searching of electronic resources. The 'higher order' skills seem to be taught less frequently and annotations on survey forms confirmed that they might be taught in the academic courses, while others noted repeatedly that the most basic computer and other academic skills such as reading, thinking and understanding the research process were lacking in students and should be explicitly taught as well. Such observations were also apparent from open-ended responses to the earlier survey, where for example one respondent, concerned about the lack of information literacy among students at that particular institution, mentioned that about $60 \%$ of students were not computer literate and $70 \%$ not 'library literate'.

\section{Issues of concern}

The results of these surveys reinforce previous findings as discussed in detail by De Jager and Nassimbeni (2002a). Behrens, for example, had commented that South African librarians by and large did not document and publish their information literacy activities (1993:125). The poor response to the first questionnaire (12 institutions out of 26 replied) and its evidence of fully accredited courses at only four institutions, led the authors to believe that librarians are still relatively unwilling to document their information literacy activities, so that discussion fora such as those provided at LIASA conferences will remain important to assist information literacy practitioners in the spread of information about activities and the dissemination of best practice.

It was noted with concern that parent institutions still by and large do not acknowledge the role of information literacy in their strategic mission statements. Librarians seem to realise that they have a role to play (for example by lobbying, which was supported by the second survey), but this does not seem to be happening to any large extent at present. Bruce (1994) had emphasised that for the successful introduction of information literacy programs, champions were required at the highest levels of institutional governance. This support by and large still seems lacking in South Africa.

The second survey supported findings from the first that information literacy practitioners understand that the competencies and skills required for effective information handling are best taught when they are fully integrated into the subject curricula and taught by librarians and academics in partnership. At the same time such partnerships have not been realised to any considerable extent in South Africa and it seems that a need will remain for generic courses to be taught for some time to come. The additional implicit assumption; that information skills are transferable and an essential component of lifelong learning, has not yet been thoroughly investigated or tested either.

Both the surveys and the published literature and reports indicate that information literacy practitioners realise that courses should be assessed. Most published reports on the assessment of information literacy interventions, however, were based on primarily favourable subjective student evaluations, which did not attempt to quantify the amount learnt or the extent to which the interventions made any difference to the student learning experience. (De Jager and Nassimbeni, 1998: I39-I43; Fourie and Van Niekerk, 200 I: II5-I I6). 


\section{Towards designing a curriculum}

At the presentation of the first survey findings at the LIASA 2002 conference, a suggestion was made to the audience that one way to continue this debate would be to present a full-day workshop on information literacy curricula, standards and assessment for South African tertiary institutions as a pre-conference at the LIASA 2003 conference. The final question in the second distributed survey therefore asked about support for such a workshop. The results were very positive indeed: 30 of the 32 respondents replied that they would be interested in attending and participating in such a workshop.

One useful guide for developing an information literacy curriculum, and one which may be useful in preparations for the proposed workshop, is Characteristics of best practice programming, developed as part of the ACRL Best Practices Initiative (Kirk, 200I), which documented the requirements for an effective information literacy programme as follows:

An information literacy curriculum should demonstrate the following characteristics:

I. A mission statement considering anticipated contributions and benefits

2. Goals and objectives taking into account sound pedagogical practice

3. Result from careful planning at programme, curriculum and institutional levels

4. Demonstrate support from both administration and institution

5. Articulate with the curriculum with emphasis on contextual learning

6. Result from collaboration between academic and library staff

7. Pedagogy: multi-disciplinary approach supporting student-centred learning

8. Adequate staff with appropriate expertise

9. Publicity and outreach

10. Assessment fully integrated (Kirk 200I).

Based on the measure of consensus achieved by the surveys as described above, it is therefore proposed that these characteristics, together with the steps and activities set out under the headings of orientation, integration and internalisation as proposed above, could form the main components of an information literacy curriculum and could provide the basis for discussion at the proposed workshop in 2003.

\section{Conclusion}

Among librarians there has been a discernible shift away from being satisfied with the stand-alone, generic model for information literacy programmes towards the recognition that integration into subject curricula is a more effective approach to information literacy training. In order to reinforce and build upon this recognition, it is necessary to develop and enhance the sharing of best practices through more careful documentation and publication of successful interventions. Success should be measurable; this logically leads to a need for objective assessment and the establishment and recognition of standards to demonstrate improvement in performance.

\section{Acknowledgement}

This paper has been based upon work supported by the National Research Foundation under Grant number 2047359.

\section{References}

Association of College and Research Libraries. (2000). Information literacy competency standards for higher education. [Online]. Available: $h t t p: / / w w w . a l a . o r g / a c r l / i l i n t r o . h t m l$ [ accessed on: March 20, 2002]

Behrens, Shirley J. (1993). User education at tertiary level: a review of recent literature. South African journal of library and information science, 61(3), 124-130.

Behrens, Shirley J. (1994). A conceptual analysis and historical overview of information literacy. College and research libraries, 55(4), 309-322.

Bruce, Christine Susan. (1994). Information literacy blueprint. [Online]. Available: http://www.gu.edu.au/text/ins/lils/infolit/ resources/blueprint/home.html [ acessed on: March 20, 2002]

Council of Australian University Librarians.(200I). Information literacy standards. Canberra: Council of Australian University Librarians. [Online]. Available: http://www.anu.edu.au/caukl/caul-doc/InfoLitStandards200I.doc. [ accessed on:March 7, 2002].

De Jager, Karin and Nassimbeni, Mary. (1998). Roadmaps for the highway: the evaluation of an information literacy training programme for South African students. Education for information, 16(2), |3|-|43.

De Jager, Karin and Nassimbeni, Mary. (2002a). Institutionalising information literacy in tertiary education: lessons learned from South African programs. Library Trends, 5 I (2): 167- 84.

De Jager, Karin and Nassimbeni, Mary. (2002b). Can they and do they: Exploring information literacy tuition in South African tertiary institutions. LIASA Conference 2002: Revitalising and creating a vibrant library world in the $2 I^{\text {st }}$ century. Port Elizabeth, 30 September-4 October. [Online]. Available: http://home.imaginet.co.za/liasa/2002papers.htm (accessed on: March 7 2003).

Fourie, Ina and Van Niekerk, Daleen. (200I). Follow-up on the use of portfolio assessment for a module in research information skills: an analysis of its value. Education for information, 19, 107-126.

Godwin, Peter. (200I). Information skills benchmarks. [Online]. Available: http://www.lisa.sbu.ac.uk/essentials/services/ benchmarks.html. [accessed on March 15, 2002].

SA Jnl Libs \& Info Sci 2003, 69(2) 
Häberle, Nikky. (200I). Developing a framework for information literacy interventions. Thesis M.Tech. Faculty of Education. Cape Technikon.

Kirk, Tom. (200I). Information literacy best practices. [Online]. Available: http://www.acad.sunytccc.edu/library/infolit/best.htm [accessed on March 14,2002$]$.

Meade, Philip H. (1998). A guide to benchmarking. Otago: University of Otago.

Sayed, Yusuf and De Jager, Karin. (1997). Towards an investigation of information literacy in South African students. South African journal of library and information science, 65(I), 5-12.

Sayed, Yusuf. (1998). The segregated information highway. Cape Town, South Africa: University of Cape Town Press.

SCONUL. (1999). Information skills in higher education: a SCONUL position paper. [Online]. Available: http://www.sconul.ac.uk/ 99104Revl.doc (accessed on: March 20, 2002].

South Africa. Department of Trade and Industry. (2000). Green Paper on Electronic Commerce. [Online]. Available: http:// www.polity.org.za/govdocs/green_papers/greenpaper/theme4.html [accessed:, March 7 2003].

South African Qualifications Authority. 2000. NQF: an overview. Available at http://www.saqa.org.za/ [accessed on: March 7, 2003]. 